\title{
Development and initial validation of a cost-effective, re-usable, ultrasound-compatible suprapubic catheter insertion training simulator
}

Harkanwal Randhawa; Yuding Wang; Jen Hoogenes; Michael Uy; Bobby Shayegan; Anil Kapoor; Edward D. Matsumoto

Department of Surgery, Division of Urology, McMaster University, Hamilton, ON, Canada

Cite as: Randhawa H, Wang Y, Hoogenes J, et al. Development and initial validation of a costeffective, re-usable, ultrasound-compatible suprapubic catheter insertion training simulator. Can Urol Assoc J 2021 September 24; Epub ahead of print. http://dx.doi.org/10.5489/cuaj.7373 Published online September 24, 2021

Corresponding author: Dr. Edward D. Matsumoto, Department of Surgery, Division of Urology, McMaster University, Hamilton, ON, Canada; matsumo@mcmaster.ca

$* * *$

\begin{abstract}
Introduction: Suprapubic catheterization (SPC) is a fundamental skill required of urology trainees. A lack of affordable simulation models and unpredictability of bedside SPCs limit experiential learning opportunities. Our objective was to develop and initially validate a reusable, low-cost, ultrasound (US)-compatible SPC simulator for acquiring skills that transfer to the bedside.
\end{abstract}

Methods: The model was constructed using six components. Staff urologists and interventional radiologists (IRs) conducted a SPC and rated the model on three domains with multiple subcategories on a five-point Likert scale: anatomic realism; usefulness as a training tool; and global/overall reaction. Participants in our first-year urology "boot camp" received SPC training, practiced, and were evaluated via an objective structured clinical examination (OSCE). Staff ratings and OSCE scores determined the model's initial face and content validity.

Results: Twelve staff physicians participated in the study. The mean scores for urologists and IRs, respectively, were: anatomical realism: 4.10 and 3.70; usefulness as a training tool: 4.23 and 4.24; and overall reaction: 4.40 and 4.44. Staff strongly agreed that the model should be incorporated into the residency curriculum. Over the past four years, 25 boot camp participants scored a mean of $99.7 \%( \pm 1.8)$ on the OSCE, with high technical performance and entrustment scores (4.8 and 4.7, respectively). The model cost \$55 CAD.

Conclusions: This novel, multiple-use, low-cost, easily reproducible US-compatible SPC simulator demonstrated initial face and content validity via high staff urologist and IR ratings 
and OSCE scores of first-year urology residents. Additional research is required for construct validation.

\section{Introduction}

Acute urinary retention (AUR) is one of the most common urologic emergencies, and a cause of significant patient discomfort. Some AUR prevalence estimates suggest that approximately 10\% of men in their eighth decade of life and $33 \%$ of men in their ninth decade will experience at least one episode of AUR, which is leading to increased hospitalization rates in elderly patients. ${ }^{1-}$ ${ }^{3}$ AUR is considered a urologic emergency, as the inability to empty the bladder requires immediate intervention, most often managed via urinary diversion. Although diversion is usually performed with urethral catheterization, in instances where access to the bladder per urethra cannot be accomplished (even with cystoscopic guidance), percutaneous suprapubic catheterization (SPC) is warranted. SPCs are conducted frequently enough that it is a fundamental skill for urologists to know and for urology trainees to learn during residency. ${ }^{4}$ Approximately $25-37 \%$ of SPC insertions are performed in the emergency setting, ${ }^{5,6}$ and safe and successful catheterization is often required of junior residents. ${ }^{7,8}$ In addition to providing immediate relief from AUR and its associated complications for the patient, making the decision to opt for SPC at the appropriate point in management can be an important factor for long-term patient outcomes. Although it has been well-documented that improper urethral catheterization serves as a major risk factor for urethral stricture disease, ${ }^{7-11} \mathrm{SPC}$ may also result in complications leading to significant morbidity, including sepsis, intra-abdominal visceral injury, and bladder neck injury, sometimes with long-term sequelae to the patient. ${ }^{12,13}$ As such, competent implementation of SPC may spare patients undue iatrogenic harm.

Unfortunately, SPC training is often limited for residents, with a major contributing factor being the lack of accessible, inexpensive, and easily reproducible and reusable simulation models. While several SPC simulators have been previously described in the literature, to our knowledge only two reports of cost-effective ultrasound (US)-compatible SPC simulators have been described. ${ }^{4,14,15}$ With increasing availability of bedside US, especially in the emergency room, the Canadian Association of Radiologists and the British Association of Urological Surgeons have advocated for the utilization of US in conjunction with SPC by operators familiar with, and trained in, its use. ${ }^{16,17}$ This is in large part to help mitigate the risk of inadvertent iatrogenic bowel injury as a result of SPC, which is estimated to occur in approximately $0.7 \%$ $2.7 \%$ of procedures and can confer significant morbidity, with an associated mortality rate of $1.8 \%{ }^{5,13,14}$ The use of US is associated with a lower injury rate when compared to blind SPC insertions. $^{14}$ 
The objective of this study was to develop and validate a bedside SPC simulation model that is cost-effective, reproducible, and reusable, while providing realistic visual and tactile feedback and the ability to use US guidance throughout the procedure. A validated SPC model would allow trainees to practice the task in a simulated environment with adequate time to safely develop the skills required for SPC with US guidance, which in turn would facilitate procedural competency that can be transferred to the bedside.

\section{Methods}

\section{Construction of the SPC model}

The SPC simulator was developed using six primary components (Figure 1). A plastic shoeboxsize container with a snap-on lid served as the housing for the components. At one end of the lid, a $12 \mathrm{~cm} \times 12 \mathrm{~cm}$ hole was cut to allow for an access point. The distended bladder was simulated using a $3 \mathrm{~L}$ normal saline or sterile water irrigation bag wrapped with a rubber tourniquet to place it under pressure. The rectum was simulated using a $100 \mathrm{~mL}$ bag of normal saline injected with red food colouring and placed directly beneath the simulated bladder. A $10 \mathrm{~cm} \mathrm{x} 10 \mathrm{~cm} \mathrm{x} 1.5 \mathrm{~cm}$ block of agar prepared from a mold was placed on top of the bladder to represent the subcutaneous layer. A purchased silicone skin model without layers (Limbs and Things, Bristol, $\mathrm{UK})$ cut to $14 \mathrm{~cm} \times 14 \mathrm{~cm}$ was placed on top of the agar and the lid was closed with the hole on top of the skin model, holding the components tightly in place (Figure 2A).

To simulate use during a clinical scenario, a sterile drape is placed over the model with a hole exposing the field (Figure 2B). The supplies required for the simulated SPC include a SPC introducer kit, a subcutaneous needle with a pre-filled syringe (or use of a vial) to simulate administration of local anesthetic, a syringe $(10 \mathrm{~mL}$ with sterile water) for inflating the catheter balloon, and ultrasound gel (Figure 1). The sterile drape and sterile gloves (reusable for this purpose) are used during simulation of the entire procedure. For bedside simulation, a $3.5 \mathrm{MHz}-$ $6.5 \mathrm{MHz} \mathrm{MHz}$ curvilinear US probe with settings optimized for superficial abdominal scanning is used. All primary components of the model are reusable for simulation purposes, with use of waterproof tape to seal the puncture hole between attempts. This model and the components cost a total of \$55 CAD. Each item and its associated costs are listed in Table 1.

\section{SPC model validation}

To assess the face and content validity of the SPC model, staff urologists and interventional radiologists (IRs) tested the simulator using US guidance. This study was conducted at multiple sites of a tertiary care health network, where urologists tested the model in the clinic setting with a portable US machine and the IRs tested the model in the radiology lab (Figure 3). The regional research ethics board approved this study.

Following a simulated SPC under US guidance, each participant evaluated the model on three domains: anatomic realism, usefulness as a training tool, and overall/global reaction to the 
model. Each domain included multiple questions which were ranked on a 5-point Likert scale. Additional demographic data were collected, including age, sex, specialty, years in practice, and approximate number of SPCs conducted. The questionnaire is available in Appendix A. The model was also used for simulation training and evaluation for first-year urology trainees during a newly developed multi-institutional urology-specific boot camp. ${ }^{18}$ A core practical component of the boot camp curriculum focuses on the management of AUR, including performing SPC. The first four years of the boot camp (2017-2020) included the use of the SPC model for training and evaluation using US guidance. The objective of this training was to introduce the indications and technique for conducting SPC and prepare trainees to independently perform the procedure during simulation and in an emergency clinical setting. Following a didactic and simulation teaching session, participants were provided time to practice SPC on the model with feedback from senior residents and staff urologists (Figure 4), after which an objective structured clinical examination (OSCE) was employed to evaluate trainee competency in the fundamentals of SPC. Trainees were provided the opportunity to perform multiple untimed attempts at SPC with US (minimum of two per trainee) during the 2-hour practical session, followed by one attempt during a timed, 10-minute OSCE. Multiple models were made available for practice during the simulation-based sessions. The materials used for the model were identical for practice and the OSCE and were consistent across the four years. Domains assessed during the OSCE included knowledge of the procedural steps, technical performance, visuospatial skills, efficiency and flow, entrustment, and overall performance. The OSCE station assessment form is available in Appendix B. Descriptive statistics for all analyses were performed using IBM SPSS Statistics ${ }^{\circledR}$ v27 (Armonk, NY).

\section{Results}

\section{Outcome and assessment measures}

Seven urologists and 5 IRs participated in the initial validation of the SPC model using US guidance. Urologist and IR participant characteristics are shown in Table 2. All participants were male and had a mean age of $43.4( \pm 7.6)$. On average, participants were in practice for $10.6( \pm 7.4)$ years (range 2-23 years), and the median number of SPCs performed was 50 (range 5-200 for urology; 5-1000 for IR).

Participants responded to 16 questions about the model's anatomic realism and its utility for teaching purposes. On the 5-point Likert scale, higher scores indicated stronger agreement with the statement. The questionnaire was divided into three domains: anatomic realism (6 questions), usefulness as a training tool (5 questions), and overall/global reaction (5 questions). The detailed results from each domain are described in Table 3, including mean scores and standard deviations (SDs) for urologists, IRs, and in aggregate. With respect to all rated items, 
for urologists the mean scores ranged from 4.0-4.6, for IRs they ranged from 3.0-4.8, and in aggregate the range was 3.7-4.6. The overall domain scores were similar between groups. 'Anatomic realism' was scored the lowest among the domains, with urologists', IRs', and aggregate scores of $4.1( \pm .95), 3.7( \pm .84)$, and $3.9( \pm .94)$, respectively. The domain 'usefulness as a training tool' received the second-highest scores, with urologists', IRs', and aggregate scores of $4.2( \pm .89), 4.2( \pm .85)$, and $4.2( \pm .89)$, respectively. 'Overall/global reaction' was rated the highest aspect of the model, with almost identical response scores from urologists, IRs, and in aggregate of $4.4( \pm .86), 4.4( \pm .80)$, and $4.4( \pm .84)$, respectively.

A total of 25 first-year urology residents (average 6 residents per cohort) participated in the multi-institutional urology boot camp (held annually in the first month of residency from 2017-2020) and were evaluated on the SPC model with US via an OSCE scored by senior residents and staff urologists. ${ }^{18}$ The OSCE station form can be found in Appendix B. Table 4 shows the detailed results by year of 5-point Likert scale ratings (mean and SD) for the following categories: knowledge of procedural steps; technical performance; visuospatial skills; efficiency and flow; entrustment; and overall performance. The mean scores ranged from 4.52-4.85 for these items across all years. The mean percentage total score (and SD) per year is noted in Table 4, which also takes into account the task ratings of the use of sterile technique, identifying the appropriate landmark, use of local anesthetic, needle aspiration of urine to confirm bladder placement, and insufflation of the catheter balloon. The total OSCE scores across all years remained above $96 \%$, with an aggregate score for all years of $99.7 \%( \pm 1.8)$.

\section{Discussion}

Proficiency in performing SPC reduces the chances of complications such as bowel injury, bladder injury, and sepsis, which can lead to poor patient outcomes. ${ }^{13}$ The urgency and unpredictability of these cases means that teaching and learning SPC is often done sporadically, which can hinder the learning process. Simulation provides an excellent opportunity for trainees to practice in a risk-free environment with feedback from instructors; however, commercial SPC simulators can be prohibitively expensive for some training programs, reaching into the thousands of dollars. ${ }^{19,20}$ The lack of US compatibility in most available models substantially limits the training experience, as SPC under US guidance improves its success and has become established in clinical practice guidelines. ${ }^{16,17}$ To address the need for an accessible and valid model, our team successfully developed, evaluated, and initially validated an inexpensive, reproducible, and reusable US-compatible SPC trainer.

Our SPC trainer (Figure 1) was composed of six primary components that combined to cost $\$ 48$ CAD (Table 1). This cost could be reduced if the contents do not need to be purchased from a medical supply company (e.g., rubber tourniquet, irrigation bags, SPC introducer kit, US conductive gel). A small amount of red food colouring for the simulated rectum and waterproof tape for resealing the punctures were not included in the overall cost (approximately \$7 CAD). 
To our knowledge, no SPC simulators with the ability be used consecutively more than once have been described in the literature. ${ }^{4}$ Our model can be used up to seven times, after which the 3L irrigation bag needs to be replaced. An ideal training model is one that can be used to allow rapid cycling of simulations during teaching workshops, ${ }^{8}$ and we were able to demonstrate this ability during boot camp.

The results of the urologist and IR evaluations suggest that the SPC model has face and content validity for the domains of anatomic realism, usefulness as a training tool, and overall/global reaction. While the IRs ranked some of the categories slightly lower than the urologists, all ratings were a 3 or higher on the 5-point scale of agreement, with the aggregate mean scores rated at 3.7 or higher (Table 3). The 12 evaluators had significant experience in performing SPC with a median of 50 cases for urologists and 100 cases for IRs (Table 2), which is past the learning curve. ${ }^{21,22}$ This clinical experience increases the likelihood that their subjective assessments of the model are valid. ${ }^{23}$

Evaluating the use of the SPC model in trainees over four consecutive years of the boot camp for incoming residents was valuable to the initial validation process. Following a didactic component, participants had ample time to practice SPC on the model with feedback prior to formal assessment. The OSCE scores of $96 \%$ or higher each year (Table 4), suggests that this training approach would be a useful component of the formal urology curriculum. This is supported by the urologists and IRs in their evaluation, as all responses were 4.3 or higher for this item (Table 3). The didactic and practical training (including portable US) components were identical across the four years.

Using US during SPC is associated with a lower risk of visceral injury than blind SPC. ${ }^{14,16,17,23,24}$ Of the six SPC models previously described in the literature, only two were reported to be US-compatible., ${ }^{4,14,15}$ Including both urologists and IRs was vital to the evaluation of our model. For the survey item "the ultrasonography looks realistic", urologists rated it a mean score of 4.0 and the IRs a 4.2, indicating its face validity as an US-compatible model. Figure 3 shows the portable and IR US monitors with the introducer entering the simulated bladder. To our knowledge, this is the first SPC model to include a simulated rectum, which can also be visualized via US. Using US to follow the introducer into the bladder and recognizing where to stop before puncturing the rectum was a valuable teaching component. Red food colouring was used to depict whether the rectum was punctured, allowing learners to have visual and tactile feedback. Tactile feedback is important for this training, as an US machine may not always be readily available when a SPC is required. The evaluators rated the model "Useful for teaching SPC insertion without US" a mean of 4.0, while the item "Entry to "bladder" feels realistic" received a mean score of 3.7, suggesting that the model successfully simulates the physical elements of SPC. A realistic sense of touch and tactile, or haptic, feedback improves surgical simulation learning, ${ }^{25}$ increasing the model's fidelity and the successful transfer of skills 
to the clinical setting. ${ }^{26}$ The model received high ratings in the anatomic realism domain, including touch and feel of the model by hand and via the use of instruments during the subcutaneous lidocaine injection, incision, and entry of the catheter (Table 3).

This study does have some limitations. The sample size for the evaluators was small, with 7 staff urologists and 5 IRs; however, both groups had significant experience conducting SPCs. Additionally, the evaluations were conducted on different US machinery, as the IRs performed the task in the radiology suite, while the urologists used portable US machines. To assess the validity of the model, it was necessary for the evaluators to perform the simulation under their normal conditions. While we did not record the time to task completion, it will be essential to record completion times and error rates in future research for construct validity. Additionally, under the "anatomic realism" domain of the assessment tool, entry to the "bladder" was evaluated without a separate assessment of the simulated rectum. As we continue to optimize and further evaluate the model for validity, the realism of the simulated rectum will be assessed as a separate structure.

During the four boot camp sessions, we were limited to assessment using OSCE methodology, as SPC comprised one of the stations on the final day. We minimized rater bias by ensuring all assessors underwent identical training for the SPC OSCE. Additionally, the didactic training and assessment metrics (Appendix B) were identical across all years, and the boot camp participants were provided ample time during the practical sessions to practice on the model while receiving feedback from senior residents and staff urologists. As this study was designed for initial face and content validation, it was beneficial to obtain OSCE-based evaluations to determine whether the model closely mimics the full procedure in trainees. These preliminary steps have laid the groundwork for further validation of the model. The Objective Structured Assessment of Technical Skills (OSATS) ${ }^{27}$ may provide additional data on skill acquisition with this model, which will be explored in future research. Importantly, both the OSCE and OSATS are validated objective measures of assessing performance. It is notable that, to our knowledge, we are the first group to objectively evaluate a SPC model. ${ }^{14}$

We also plan to evaluate the model during our urology residency program's annual point of care US (POCUS) course, which currently does not have a SPC evaluation component. ${ }^{30}$ This course is conducted during an academic half-day and all urology residents in our program attend, which allows for evaluation of residents at different levels of training. To explore options, during the most recent course, we used a thin pork chop with a bone (to simulate the pubic symphysis) to simulate the skin layer and subcutaneous tissue on the SPC model, which worked very well for US training, ${ }^{30}$ indicating a potential improvement to the model. This variation will need to be tested before any training for evaluation purposes occurs.

The next steps in the validation of our SPC model include determining its construct validity. The SPC simulator must show that performance on the model does not discriminate 
between naïve and experienced urologists and IRs and that, procedurally, the model closely represents SPC performed in the practice setting. This demonstrated ability to transfer skills from the model to the bedside will also confirm its predictive and concurrent validity. ${ }^{28,29}$ Once construct validity is demonstrated, the model may be used to assess trainee competence using OSATS, ${ }^{27,31}$ which would provide support for its inclusion in competency-based urology residency curricula.

\section{Conclusions}

Our team developed and initially validated a novel SPC model that is US-compatible, low in cost, and reusable. The simulator received high ratings from staff urologists and IRs across multiple domains, including anatomic realism, its use as a training tool, and recommendation for inclusion in urology residency curricula. Additionally, the model was successfully used across four years of a multicenter annual urology boot camp for incoming residents. Trainees across all years scored a mean of $99.7 \%( \pm 1.8)$ on a standardized SPC OSCE. While the model shows initial face and content validity, additional research is warranted to determine its construct validity and transferability from a simulated to a clinical setting. With the recent paradigm shift to competency-based medical education, this model may eventually serve as a validated evaluation tool for SPC competency. This low-cost, accessible SPC simulator can be easily adopted by urology residency programs.

\section{References}

1. Armitage JN, Sibanda N, Cathcart PJ, et al. Mortality in men admitted to hospital with acute urinary retention: database analysis. BMJ 2007;335:1199-202.

2. Marshall JR, Haber J, Josephson EB. An evidence-based approach to emergency department management of acute urinary retention. Emerg Med Pract 2014;16:1-20.

3. Yoon PD, Chalasani V, Woo HH. Systematic review and meta-analysis on management of acute urinary retention. Prostate Cancer Prostatic Dis 2015;18:297-302. 
4. Nonde J, Adam A, Laher AE. Validation of a low cost, disposable, and ultrasound-guided suprapubic catheter insertion trainer. Urology 2018;115:45-50.

5. Hall S, Ahmed S, Reid S, et al. A national UK audit of suprapubic catheter insertion practice and rate of bowel injury with comparison to a systematic review and metaanalysis of available research. Neurourol Urodyn 2019;38:2194-9.

6. Khan A, Abrams P. Suprapubic catheter insertion is an outpatient procedure: cost savings resultant on closing an audit loop. BJU Int 2009;103:640-4.

7. Singal A, Halverson A, Rooney DM, Davis LM, Kielb SJ. A validated low-cost training model for suprapubic catheter insertion. Urology 2015;85:23-6.

8. Hossack T, Chris BB, Beer J, Thompson G. A cost-effective, easily reproducible, suprapubic catheter insertion simulation training model. Urology 2013;82:955-8.

9. Fenton AS, Morey AF, Aviles R, Garcia CR. Anterior urethral strictures: etiology and characteristics. Urology 2005;65:1055-8.

10. Lumen N, Hoebeke P, Willemsen P, De Troyer B, Pieters R, Oosterlinck W. Etiology of urethral stricture disease in the 21st century. J Urol 2009;182:983-7.

11. Mundy AR, Andrich DE. Urethral strictures. BJU Int 2011;107:6-26.

12. Nyman MA, Schwenk NM, Silverstein MD. Management of urinary retention: rapid versus gradual decompression and risk of complications. Mayo Clin Proc 1997;72:951-6.

13. Ahluwalia RS, Johal N, Kouriefs C, Kooiman G, Montgomery BS, Plail RO. The surgical risk of suprapubic catheter insertion and long-term sequelae. Ann R Coll Surg Engl 2006;88:210-3.

14. Nonde J, Laher AE, McDowall J, Adam A. A systematic review of the world of validated suprapubic catheter insertion simulation trainers: From 'head-blocks' to 'lunch boxes'. Curr Urol 2020;13:179-188.

15. Palvolgyi R, Lee A, Ramirez F, Durbin-Johnson B, Rothschild J, Yang J. VesEcho training system: Suprapubic catheterization under ultrasound guidance. Urol Pract 2018;5:63-68.

16. Harrison SC, Lawrence WT, Morley R, Pearce I, Taylor J. British Association of Urological Surgeons' suprapubic catheter practice guidelines. BJU Int 2011;107:77-85.

17. Chawla T, Cresswell M, Dhillon S, Greer MC. Reply to "A multidisciplinary response to the Canadian Association of Radiologists' Point-of-Care Ultrasound Position Statement". Can Assoc Radiol J 2020;71:138-9.

18. Wang Y, Hoogenes J, Clark R, et al. Development, implementation, and evaluation of a competency-based didactic and simulation-focused boot camp for incoming urology residents: Report of the first three years. Can Urol Assoc J 2021;15:98-105.

19. GT Simulators. Available at: https://www.gtsimulators.com/products/suprapubiccatheterization-training-model-ar341 Accessed 20 March 2021

20. Limbs \& Things. Available at: https://limbsandthings.com/uk/products/60852/60852suprapubic-unit-for-catheterization-trainer/ Accessed 20 March 2021

21. Abboudi H, Khan MS, Guru KA, Froghi S, de Win G, Van Poppel H, Dasgupta P, Ahmed K. Learning curves for urological procedures: a systematic review. BJU Int 2014;114:617-29. 
22. Brunckhorst O, Volpe A, van der Poel H, Mottrie A, Ahmed K. Training, simulation, the learning curve, and how to reduce complications in urology. Eur Urol Focus 2016;2:108.

23. Schout BM, Hendrikx AJ, Scheele F, Bemelmans BL, Scherpbier AJ. Validation and implementation of surgical simulators: A critical review of present, past, and future. Surg Endosc 2010;24:536-46.

24. Jacob P, Rai BP, Todd AW. Suprapubic catheter insertion using an ultrasound-guided technique and literature review. BJU Int 2012;110:779-84.

25. Ström P, Hedman L, Särnå L, Kjellin A, Wredmark T, Felländer-Tsai L. Early exposure to haptic feedback enhances performance in surgical simulator training: a prospective randomized crossover study in surgical residents. Surg Endosc 2006;20:1383-8.

26. Prystowsky JB, Regehr G, Rogers DA, Loan JP, Hiemenz LL, Smith KM. A virtual reality module for intravenous catheter placement. Am J Surg 1999;177:171-5.

27. Martin JA, Regehr G, Reznick R, MacRae H, Murnaghan J, Hutchison C, Brown M. Objective structured assessment of technical skill (OSATS) for surgical residents. $\mathrm{Br} J$ Surg 1997;84:273-8..

28. Fried MP, Satava R, Weghorst S, Gallagher AG, Sasaki C, Ross D, Sinanan M, Uribe JI, Zeltsan M, Arora H, Cuellar H. Identifying and reducing errors with surgical simulation. Qual Saf Health Care 2004;13:S19-S26.

29. Sutherland LM, Middleton PF, Anthony A, Hamdorf J, Cregan P, Scott D, Maddern GJ. Surgical simulation: a systematic review. Ann Surg 2006;243:291-300.

30. Uy M, Lovatt CA, Hoogenes J, Bernacci C, Matsumoto ED. Point-of-care ultrasound in urology: Design and evaluation of a feasible introductory training program for Canadian residents. Can Urol Assoc J 2021;15:E210-E214.

31. Ahmed K, Miskovic D, Darzi A, Athanasiou T, Hanna GB. Observational tools for assessment of procedural skills: A systematic review. Am J Surg 2011;202:469-480.

\section{Figures and Tables}

Fig. 1. Suprapubic catheterization model components. 


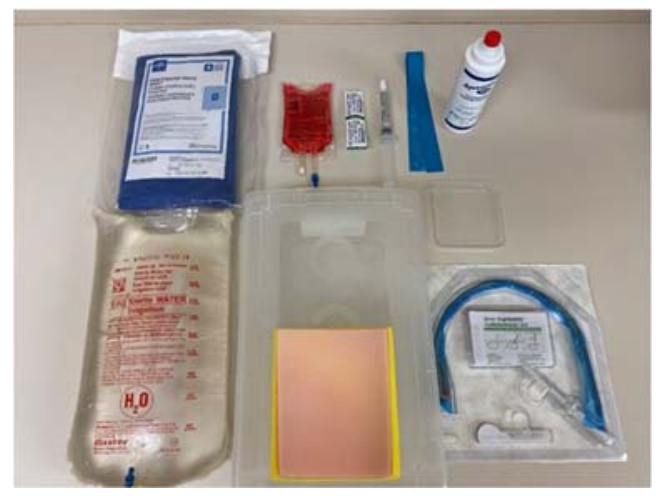

Fig. 2. Suprapubic catheterization model (A) and when draped (B).

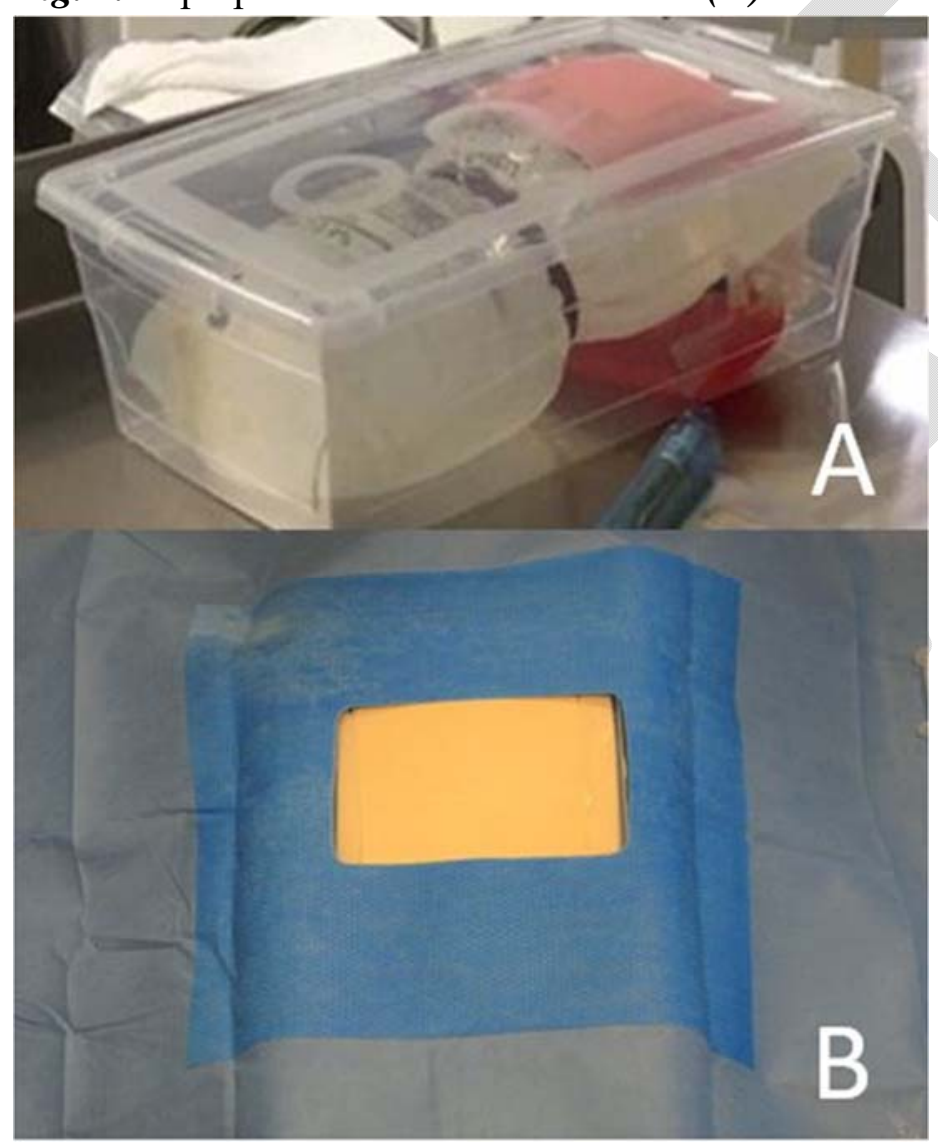

Fig. 3. Suprapubic catheterization model in use with ultrasound. 


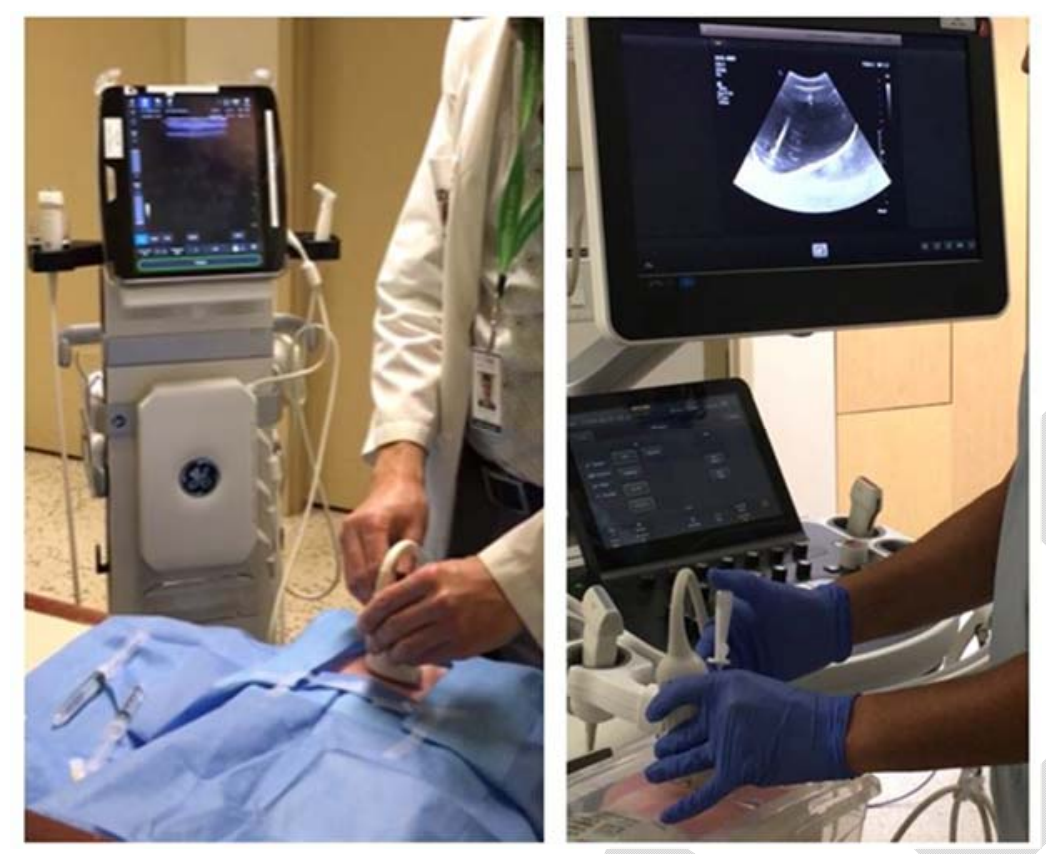

Fig. 4. Suprapubic catheterization practice during urology boot camp.

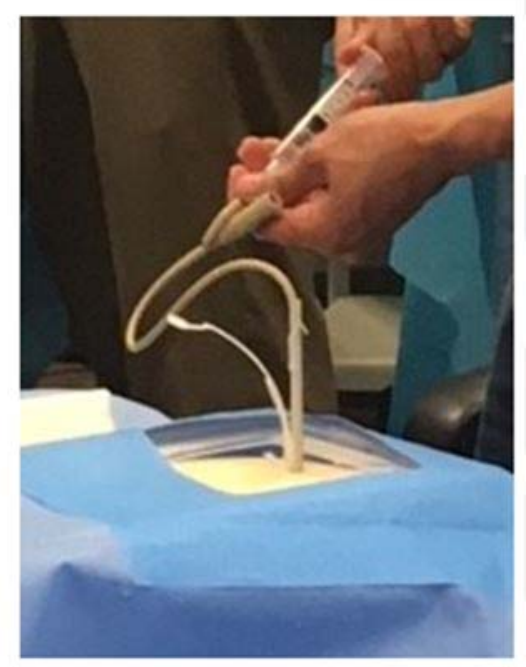

Table 1. SPC model components and cost (\$CAD) 


\begin{tabular}{|c|c|c|}
\hline Component & Material & Cost \\
\hline Bladder & $\begin{array}{l}\text { 3L normal saline or sterile water } \\
\text { irrigation bag put under pressure by } \\
\text { using a rubber tourniquet } \\
\text { Waterproof tape to seal puncture holes }\end{array}$ & $\$ 18$ \\
\hline Simulated rectum & $\begin{array}{l}100 \mathrm{~mL} \text { normal saline bag injected } \\
\text { with red food colouring } \\
\text { Red food coloring }\end{array}$ & $\begin{array}{l}\$ 5 \\
\$ 2\end{array}$ \\
\hline Skin layer & $\begin{array}{l}\text { Silicone skin model without layers, } \\
\text { purchased from medical/surgical } \\
\text { simulation company }\end{array}$ & $\$ 10$ \\
\hline Subcutaneous tissue & $\begin{array}{l}\text { Ultrasound compatible agar gelatin in } \\
\text { a } 10 \mathrm{~cm} \times 10 \mathrm{~cm} \text { mold, } 1.5 \mathrm{~cm} \text { thick }\end{array}$ & $\$ 1$ \\
\hline Housing & $\begin{array}{l}\text { Shoebox-sized plastic box with snap- } \\
\text { on plastic lid to provide stability. A } \\
\text { square portion of the lid is cut out to } \\
\text { serve as the simulated SPC site }\end{array}$ & $\$ 2$ \\
\hline $\begin{array}{l}\text { Suprapubic catheter } \\
\text { introducer kit }\end{array}$ & Obtained from medical supplier & $\$ 5$ \\
\hline Ultrasound gel & Obtained from medical supplier & $\$ 6$ \\
\hline $\begin{array}{l}\text { Drape and sterile } \\
\text { gloves }\end{array}$ & $\begin{array}{l}\text { Sterile draping (reusable for this } \\
\text { purpose) to cover the box - a hole is } \\
\text { cut into the drape to expose the } \\
\text { simulated SPC site }\end{array}$ & $\$ 1$ \\
\hline $\begin{array}{l}\text { Total cost } \\
\text { (approximate) }\end{array}$ & & $\$ 55$ \\
\hline
\end{tabular}

SPC: suprapubic catheterization.

\section{Table 2. Staff urologist and IR characteristics}

Mean value ( \pm SD) 


\begin{tabular}{|l|c|c|c|}
\hline & $\begin{array}{c}\text { Urologists } \\
(\mathbf{n = 7})\end{array}$ & $\begin{array}{c}\text { IRs } \\
(\mathbf{n = 5})\end{array}$ & $\begin{array}{c}\text { Aggregate } \\
\mathbf{( N = 1 2 )}\end{array}$ \\
\hline Age & $43(9.1)$ & $44(5.8)$ & $43.4(7.6)$ \\
\hline $\begin{array}{l}\text { Number of years in } \\
\text { practice }\end{array}$ & $10(8.3)$ & $11.4(6.8)$ & $10.6(7.4)$ \\
\hline $\begin{array}{l}\text { Number of years in } \\
\text { practice: Median } \\
\text { (range) }\end{array}$ & $12(2-23)$ & $12(1-20)$ & $144(274)$ \\
\hline $\begin{array}{l}\text { Approximate number } \\
\text { of SPCs }\end{array}$ & $67.9(65.4)$ & $251(421)$ & $50(5-1000)$ \\
\hline $\begin{array}{l}\text { Approximate number } \\
\text { of SPCs: Median } \\
\text { (range) }\end{array}$ & $50(5-200)$ & $100(5-1000)$ & \\
\hline
\end{tabular}

IR: interventional radiologist; SD: standard deviation; SPC: suprapubic catheterization. 
Suprapubic catheter insertion training simulator

\begin{tabular}{|c|c|c|c|}
\hline \multirow[t]{2}{*}{ Questionnaire item } & \multicolumn{3}{|c|}{ Mean score/5 ( \pm SD) } \\
\hline & $\begin{array}{l}\text { Urologists } \\
(n=7)\end{array}$ & $\begin{array}{c}\text { IRs } \\
(n=5)\end{array}$ & $\begin{array}{l}\text { Aggregate } \\
(\mathrm{N}=12)\end{array}$ \\
\hline \multicolumn{4}{|l|}{ Anatomic realism } \\
\hline $\begin{array}{l}\text { Anatomic structures were } \\
\text { realistic }\end{array}$ & $4.1(0.7)$ & $3.6(0.5)$ & $3.9(0.7)$ \\
\hline Anatomic size is realistic & $4.3(0.8)$ & $4.2(0.8)$ & $4.3(0.8)$ \\
\hline Tissue feels realistic (touch/feel) & $4.0(1.0)$ & $3.6(0.5)$ & $3.8(0.8)$ \\
\hline $\begin{array}{l}\text { Tissue feels realistic (incision, } \\
\text { subcutaneous injection, catheter } \\
\text { insertion) }\end{array}$ & $4.0(1.0)$ & $3.6(0.9)$ & $3.8(0.9)$ \\
\hline Entry to "bladder" feels realistic & $4.1(0.7)$ & $3.0(0.7)$ & $3.7(0.9)$ \\
\hline Ultrasonography looks realistic & $4.0(1.2)$ & $4.2(0.8)$ & $4.1(1.0)$ \\
\hline \multicolumn{4}{|l|}{ Usefulness as a training tool } \\
\hline Useful for teaching anatomy & $4.3(0.8)$ & $4.4(0.9)$ & $4.3(0.8)$ \\
\hline $\begin{array}{l}\text { Useful for teaching SPC insertion } \\
\text { without ultrasound }\end{array}$ & $4.3(0.8)$ & $3.6(1.1)$ & $4.0(1.0)$ \\
\hline $\begin{array}{l}\text { Useful for teaching SPC insertion } \\
\text { with ultrasound }\end{array}$ & $4.1(0.9)$ & $4.0(0.7)$ & $4.1(0.8)$ \\
\hline Useful for improving technique & $4.1(0.7)$ & $4.8(0.4)$ & $4.4(0.7)$ \\
\hline $\begin{array}{l}\text { Overall usefulness as a simulated } \\
\text { tool for SPC insertion }\end{array}$ & $4.3(0.8)$ & $4.4(0.5)$ & $4.3(0.7)$ \\
\hline \multicolumn{4}{|l|}{ Overall/global reaction } \\
\hline $\begin{array}{l}\text { "I would recommend the SPC } \\
\text { model for training purposes" }\end{array}$ & $4.3(0.8)$ & $4.6(0.5)$ & $4.4(0.7)$ \\
\hline $\begin{array}{l}\text { "Working with this model would } \\
\text { help trainees feel more } \\
\text { confident" }\end{array}$ & $4.6(0.5)$ & $4.6(0.5)$ & $4.6(0.5)$ \\
\hline $\begin{array}{l}\text { "This model should be } \\
\text { incorporated into the urology } \\
\text { curriculum" }\end{array}$ & $4.3(0.8)$ & $4.4(0.9)$ & $4.3(0.8)$ \\
\hline $\begin{array}{l}\text { "Skills learned using this model } \\
\text { are transferable to an in vivo } \\
\text { setting" }\end{array}$ & $4.3(0.8)$ & $4.4(0.5)$ & $4.3(0.7)$ \\
\hline $\begin{array}{l}\text { "Working with this model would } \\
\text { be as useful as working with an } \\
\text { animal model" }\end{array}$ & $4.6(0.8)$ & $4.2(0.8)$ & $4.4(0.8)$ \\
\hline
\end{tabular}

*Anatomic realism domain: 1 = "not realistic at all"; 5 = "very realistic". Usefulness as a training tool domain: 1 = "not useful at all"; 5 = "very useful". Overall/global reaction to the model: $1=$ "strongly disagree"; 5 = strongly agree". Please see Appendix A for questionnaire. IR: interventional radiologist; SPC: suprapubic catheterization.

Table 4. SPC OSCE scores from urology boot camp years 2017-2020 


\begin{tabular}{|c|c|c|c|c|c|}
\hline $\begin{array}{l}\text { OSCE item } \\
\text { Mean } \\
\text { score } / 5 \\
( \pm \text { SD })\end{array}$ & $\begin{array}{l}2017 \\
n=6\end{array}$ & $\begin{array}{c}2018 \\
n=6\end{array}$ & $\begin{array}{c}2019 \\
n=7\end{array}$ & $\begin{array}{c}2020 \\
n=6\end{array}$ & $\begin{array}{c}\text { Mean }( \pm \mathrm{SD}) \\
\text { all years } \\
\mathrm{N}=25\end{array}$ \\
\hline $\begin{array}{l}\text { Knowledge } \\
\text { of procedural } \\
\text { steps }\end{array}$ & $4.83(.41)$ & $4.00(.89)$ & $4.43(.79)$ & $4.83(.41)$ & $4.52(.79)$ \\
\hline $\begin{array}{l}\text { Technical } \\
\text { performance }\end{array}$ & 5.00 & $4.67(.82)$ & $4.29(.49)$ & $4.83(.41)$ & $4.68(.76)$ \\
\hline $\begin{array}{l}\text { Visuospatial } \\
\text { skills }\end{array}$ & 5.00 & $4.83(.41)$ & $4.57(.54)$ & 5.00 & $4.85(.69)$ \\
\hline $\begin{array}{l}\text { Efficiency } \\
\text { and flow }\end{array}$ & 5.00 & $4.83(.41)$ & $4.43(.54)$ & 5.00 & $4.82(.69)$ \\
\hline Entrustment & 5.00 & $4.00(.89)$ & $3.86(.38)$ & $4.83(.41)$ & $4.42(.75)$ \\
\hline $\begin{array}{l}\text { Overall } \\
\text { performance }\end{array}$ & 5.00 & $4.17(.75)$ & $4.14(.38)$ & $4.83(.41)$ & $4.54(.72)$ \\
\hline $\begin{array}{l}\text { Total score } \\
\%( \pm \text { SD })\end{array}$ & $99.5(1.2)$ & $99.7(1.3)$ & $96.4(7.2)$ & $97.0(3.8)$ & $99.7(1.8)$ \\
\hline
\end{tabular}

Please see Appendix B for OSCE survey. OSCE: objective structured clinical examination; SD: standard deviation; SPC: suprapubic catheterization. 